\title{
Customer Relationship Management (CRM) as a Life Style
}

\author{
Hussein A. Al-Homery ${ }^{1}$, Hasbullah Asharai ${ }^{2}$, Azizah Ahmad ${ }^{3}$ \\ ${ }^{1}$ School of Technology Management and logistic, College of Business, Universiti Utara \\ Malaysia, Malaysia. \\ ${ }^{2}$ Associate Professor, Department of Management and Humanities, Faculty of Science \& \\ Information Technology, Universiti Teknologi Petronas, Malaysia. \\ ${ }^{3}$ Institute for Advanced and Smart Digital Opportunities, School of Computing, Universiti \\ Utara Malaysia, Malaysia. \\ Email: homeryh65@yahoo.com
}

\begin{abstract}
This article is about the concept of CRM life style. It is an intellectual concept, where the researcher analyses the abbreviation "CRM" by returning each letter to its origin to prove the hypothesis of the concept. Where the researcher proposes the CRM database structure for the CRM process as a customer life style, where it depends on the business workflow process and the specialty of each business, and where the database structure tried in our case study for an authorized automobile dealer in Riyadh, Saudi Arabia.

Keywords: CRM Life Style, CRM Business Process, CRM Workflow, CRM Database Structure
\end{abstract}

\section{Introduction}

In this article, we are going to analyse the abbreviation "CRM" by returning each letter to its origin and from there we are going to build our logic. "C $\mathrm{C}$ " stands for customers. Then what customers are? Customers are either living things or non-living things. Living things such as human beings, animals, birds, all whatever live have soul, flesh and blood while non-living things are all things that exist on earth but without soul, flesh and blood like plants, company and architecture. But if we look for these abnormal categories which we divided, we found that each aforementioned category has it is own life cycle till death. Some of these life cycles fluctuate but mostly they are steady since most of those have a fixed life cycle stages. To clear our point, let us take the example of human being life cycle. The human beings born as infant in the first month of their lives, then child, kid, young man, mature man, old man, and then they reach the death stage. All these are different stages of human life cycle. In each and every stage, there are motivations and incentives which are different from one another. In born stage, the motivations and incentives are what parents have in their mind 
for their baby and those motivations and incentives constitute in their mind as a result of their education, their religious aspects, their traditions and rituals. Those are also affected by the media. In death stage, there are motivations and incentives from the person's family who take decision to pass him to his last resort. Their decision is affected by many factors such as their education, their religious regulation, and the media too. Similarly, all other stages have their own motivations and incentives for dealing with various challenges of life including buying and selling.

One thing that is imperative is the motivation which refers to something that pushes you to do a particular task. Here, the marketing and many related concepts play a big role in the life's decisions of a man. The second word incentives are something inside individuals which pushes them to do something they like. Here also, marketing, educational concepts, religious affiliations, tradition, rituals and media play a vital role in determining the incentives.

The reason of discussing all this is to reach a conclusion that in every stage of the life cycle of living as well as non-living things, they are customers. In this way, we all are customers in every stage of life from birth till death. At birth stage, we are the customer of the hospital and the clinic, then we become customer for baby shops, kids shops, young men shops, men shops, overage shops, and then we are customers for coffin shops.

A customer can be a buyer and seller at the same time. I am a salesman to sell specific kind of goods, and at the same time, I buy other products and services to fulfill my needs. These rules can be applied on all type of customers whether they are individuals or companies.

" $R$ " stands for relationship. if we look up the meaning of relationship in the dictionary we will find at least three to four meanings. Thus, we looked up the meaning in Longman dictionary and found four meanings. The first is "the way in which two people or two groups feel about each other and behave towards each other". The second is "the way in which two or more things are connected and affected each other". The third and fourth meaning tells the same story about how two individuals or groups feel and tie to each other. Therefore, the relationship is a way of communication, a way of interpretation of feelings and behaviors, or a method of understanding. Sometimes people look at each other and act without speaking. They know what the other person wants to say without speaking. It is a method of connection that keeps you able to interpret the others' actions and this happen by the nature of your communication with the others. 
If we look for relationship as a way of feeling as per our example of human beings above, we should consider five senses of human beings as a source of feelings and each of them constitutes a part in your decision making when dealing with other things or people or when taking a decision of buying and selling.

If we look for relationship as a connection or communications, it means that there should always be a way to communicate with others. Being humans, we have to communicate, we have to speak, we have to look, we have to touch, we have to listen and all these are different ways of communications. Science scholars state that the use of more than one sense in the same job get you do it in the right and perfect way because your concentration will be more in doing that job.

In today's world, we communicate, read newspapers, listen news from electronic media, we have landline phones that enable us to reach round the world in no time. Moreover, mobile phones enable us to stay in touch with others. Now, we have "LAN" Local Area Network, "WAN" Wide Area Network, "WiFi" Wireless Networking, "PSTN" Public Switch Telephony Network and so on. In other words, intranet, extranet and internet connectivity provide various forms of connections.

" $\mathrm{M}$ " stands for management. If we look for the meaning of management in Longman dictionary, it has the following meaning:

- "The activity of controlling and organizing the work that a company or organization does".

- "The people who are in charge of a company or organization".

- "The way that people control and organize different situations that happen in their lives or their work".

If we look in depth into the above meaningful explanations of the word "management", we will find that management is a way of organizing your work. In other words, putting your procedures and steps to have an organizing work environment to manage different situations in your work environment by following specific managerial approaches.

So, management of what? In our case, we have customers as living things and nonliving things and each of them have different categories, and each of these categories have their own characteristics. These data have to be stored in specific place to be handy for the management to manage such volume of business data for the sake of the organization. So, the questions is "what management has to do? The role of management here is to follow and find methods such as creating and maintaining customers' databases. These customers' databases 
will be most important characters for each category since the organizational activities and businesses need this information.

Management also manages their staff and make them capable of communicating with their customers in many ways using land phones, mobile phones, SMS, Post office mail, Email, electronic and print media. Now, the world has advanced in the field of telecommunication networking. Now, we have Ethernet LANs, Wireless LANs where we have "PANs" (Bluetooth Personal Area Networks), "RFIDs" (Radio Frequency IDs), "UWB" (Ultra-Wide Band), "4G" Fourth-generation stations, "5G", "PSTN" Public Switched Telephone Network, cellular technology, IP telephony, "WANs" Wide Area Networks, Telephone modem communications, "DSL" Digital Subscriber lines, Cable modem Service, "PSDN" Public Switched Data Networks, and "VPNs" Virtual Private Networks. Some of the technologies in networking are listed here to get the idea that how the world of telecommunications become prominent to all of us and how it can be useful to the individuals as well as management. In this era of technology, customized novel innovations are taking place on daily basis.

So, the conclusion here is that management finds or sets the ways and methods of creating, keeping and maintaining a good customers database with a good and easy way of communications for these customers as per organizational strategy.

\section{CRM Life Style Structure}

As a result of above discussion, we can sum up the CRM structure which would be maintained as a life cycle or life style database as follows:

- Customers' Data: We have customers' basic data whatever the categories are (name, address, contacts, specialized in or position, special features that data requires as per the organizational activities).

- Customers and Management: A huge volume of customers' data if it is not standardized to be known for whoever uses these databases, it would be of no use especially in a globalized world. (So, data mapping should be done as per the global standard fields of customers' database to be acceptable worldwide).

- One standard validation rules of each field of the databases set which should be classified as per the company business requirements. (Customer, Relationship, Management).

- Once you have your durable and accurate databases fields as per your business requirements then communication ways should be applied to enrich your 
customers' databases to generate your prospective business volume as per your follow up process (Customer, Relationship, Management).

Then the structure of CRM is to set your standard structure customers' database, set your validation business rules and to manage your sources of profit by fixing communication ways of enhancement your customers' relationships. The same logic is applied by the researcher in our case study of an authorized automatable dealership in Riyadh, Saudi Arabia, where we mapped our customers' database target-record to mandatory fields and optional fields as per our business process requirements of such critical data for our business. Then, we modified our standard dealership "target-record" database to the most critical few fields only. Then we designed our own "CUSAP" database as per the standard where it takes all the data from our main "target-record" database system. Then we designed our communication program follow up to enable the salesman to communicate with his customers on interval periods of time 10 days, 30 days and over 3 months, where he gets his prospective customers from these relationships to enhance business process and easy the follow up process of the customers through powerful CRM features in generating a prospective volume of business since his main business is customers only, a complete service center for customers care.

\section{Discussion of CRM database Life Style}

In late eighties, when I started my practical life in the business companies, the most important task was to have a list of your customers that includes their basic data. This list differs from one company to another. At that time, most of these lists were made on lotus 123 or framework spreadsheets. Before the end of eighties, the concept of database design started in the market DBIII, DBIII plus, and then DBV. With the launch of DBIII plus, the programming of computer concepts were changed to an easy way to understand what you want to do with some patients, thus, many users start to program by databases language (i.e. in DOS environment). Then, the wave of Windows came with a complete changes in the concepts of programming and everything become object oriented. Such concepts changed too much in business concepts and the ease of use. The ease of programming features let the businesses adopt whatever new technology in programming comes. In communication, to enable the organization to produce and gain more profits. These days, you can listen the management statements everywhere such as "We don't need any human interfere in our systems, We need every process in operations to be automated automatically by the system" especially in databases concepts and communications. Today, world has gone towards globalization. 
As per our above example from man's life cycle, the data of an infant, such as his name, his date of birth his mother's name, his father's name, is registered in the hospital where he/she is born. Then, in birth registration office, the same data is used to get a birth certificate and an ID number is given to him/her in "KSA" Kingdom of Saudi Arabia. In America, this number is known as Social ID number. Then, this data is used by his/her school (e.g. name, grade, address, and so on). Then, the university also uses his/her data thorough university database (e.g. name, address, contacts, email, social ID number and so on). The customer's data is stored in more than one place for the same government or different governments for all above purposes. Now every government has its own e-government site, where anything related to the government can be done through this website. Just login to the website and do enquiry for your job and business. So, your personal data is exposed to the world now.

Another example, if you buy a car on installments, your personal data such as salary, age, contacts, address, positions etc. is completely taken and sent to credit bureau office through the credit agent for checking your records in banks, loan organizations round the kingdom. This is done for knowing if you have ever been a defaulter before or even if paid late for your Credit Card, it will be shown in this credit bureau reports. Now, the world is using XML. The XML is not a database rather it enables you to send your data between text tags and it can communicate with all the databases. Example, if we take our "target-record" databases fields and put them in tags in the form of XML sheet and supply to our local credit bureau office, then the local credit bureau office response report shows all your records in all banks and other loans companies. As per this response report, we make another manipulation and mail the data in XML to another international credit bureau. That will give us your score in three digits. As per this score of the international office and the report of the local credit bureau, your evaluation for the credit is done regarding your eligibility. Even if you create an email in yahoo or any other site, your data has already been captured and exposed globally. So, available market research companies collect such customer data and bargain on its prices for the research they offer.

\section{Conclusion}

The above discussion concludes that, as a Customer from your date of birth, your data has already been exposed and you are aimed from more than one agency who try to get you as a customer for their products. Thus, there is a huge competition among companies to win your 
satisfaction and by fulfilling your expectation to let you feel how important you are to the companies.

There are several reasons for such a high competition among companies for customers. Since all the businesses are started for making profits, so customers are of prime importance for the businesses. Without customers, businesses are considered as dead business. Even in non-profit organizations, the customer satisfaction is a must. Thus, to gain your business profit, you have to extend your customer base. More customers mean more profits which enhances your business.

After explaining the roles of customer, relationship and management, let us have a look on the CRM business process.

\section{Discussion on CRM Business Process}

The vision of Siebel, who is considered as a godfather of CRM, is that the trend or the direction in organizations for buying CRM software is to contain their industry best practice business processes and their ways of doing business in their software.

Siebel's vision is that any business has its own activities and process. Such business process exists everywhere. Some businesses follow standard procedures while other do not. However, businesses in the same industry tend to follow same process. Since this is globalized era, people are inclined towards standards in their normal business process. Thus, following standard procedures help to achieve your targets. Reprocessing or reengineering through innovation further helps businesses to achieve their targets. Since, every organization is established for making profits and to earn profits, businesses must have customers who buy their products. Following a business procedure in which customers are not taken care of will ultimately ruin the business. Such businesses will waste the time as well as money. Thus, the main purpose of business process must be to serve the customers' needs.

Also, Siebel's vision is that the business process applications should be dominated by the web services applications. Nowadays, standard web services for business process are available in many languages such as "BPEL4WS"(Business Process Execution Language for Web Services). It is designed to specify business process built with web services. "J2EE" (Java 2 Enterprise Edition) and "UAN" (Universal Application Network) are standards-based approaches to design and develop cross-application business processes. Whereas, "UML" (Unified Modeling Language) and "WSDL" (Web Service Description Language) are based on "SOAP" (Simple object access protocol), "WSFL" (Web Service Flow Language) and "XSD” (XML Schema Definition). 
Such business process applications require information from all business models of the organization. The organizational management these days want everything to be automated by the system. So they want customized automation of business processes in each industry and it is highly recommended in the time of globalization.

If we look to our example of the man's life cycle at each stage, there are motivations and incentives according to various organizational activities. It is characterized and stored in their customer databases globally. Thus, the main concept in promoting buying and selling process is studying such motivations and incentives where the management of a software such as "CRM" can help in manipulating such features. The concept is to deal with customers' motivations and incentives in first place. Some other authors called "CPM" Customer Process Management as the soul of the future companies which require to customize your processes as per customers' demands of today and tomorrow. Therefore, it is required architectural process, not an automated process which will remove competitor differentiation. Our case here is "GM" General Motors difference Program, where they try to standardize everything in their auto dealer to reach the customer "moment of truth" where the customer becomes loyal and a lifetime customer.

\section{References}

Al-Homery, A. Hussein (2007), Customer Relationship Management for an authorized automobile dealership, Dakota State University, Master thesis.

General Motors, (2006), GM the Difference; USA.

http://findarticles.com/p/articles/mi_zdewk/is_200209/ai_ziff30812/print retrieved on 17th may 2007

http://www.kcarmour.com.au/the-death-of-the-crm/ retrieved on $27^{\text {th }}$ Jan. 2018

https://www.digitaldealer.com/crm-death-customer-interaction/ retrieved on $27^{\text {th }}$ Jan. 2018

http://www.information-age.com/crm-dead-shifting-sands-customer-engagement-123461198/ retrieved on $27^{\text {th }}$ Jan. 2018

Procter, P. (1978). Longman dictionary of contemporary English. Harlow. England: Longman. 